\title{
XÁC ĐỊNH GIÁ TRỊ SÀNG LỌC THIÉU GLUCOSE - 6 - PHOSPHATE DEHYDROGENASE CỦA PHƯƠNG PHÁP ĐO HOẠT Độ ENZYM TRÊN MÃU MÁU THÂM KHÔ
}

\author{
Trần Thị Chi Mai ${ }^{1,2, 凶}$, Nguyễn Thị Phương Cúc ${ }^{3}$ \\ ${ }^{1}$ Trường Đại học Y Hà Nội, \\ ²Bệnh viện Nhi Trung ương, \\ ${ }^{3}$ Trường Đại học kỹ thuật Y tế Hải Dương
}

Sàng lọc thiếu G6PD ở trẻ sơ sinh cho phép bác sĩ nhi khoa chẩn đoán và có biện pháp phòng ngừa, điều trị thích hợp từ rất sớm, nhờ vậy giảm thiểu các tình trạng vàng da nặng liên quan đến thiếu G6PD ở trẻ sơ sinh. Nghiên cứu này được tiến hành nhằm đánh giá giá trị của phương pháp đo hoạt độ enzym trên mẫu máu thấm khô để sàng lọc thiếu G6PD. Phân tích đường cong ROC cho thấy xét nghiệm có diện tích dưới đường cong bằng 1. Tại điểm cắt tối ưu 2,565 IU/g Hb, độ nhạy và độ đặc hiệu trong chẩn đoán thiếu G6PD đều là $100 \%$. Xét nghiệm đo hoạt độ enzym trên mẫu máu thấm khô sử dụng kit của Perkin Elmer có giá trị tốt trong sàng lọc thiếu G6PD.

Từ khóa: Thiếu G6PD, Sàng lọc sơ sinh, mẫu máu thấm khô, đo hoạt độ enzym

\section{I. ĐĂT VẤN ĐÊ}

Thiếu Glucose - 6 - phosphat dehydrogenase (G6PD) là một trong các bệnh thiếu enzym di truyền gen lặn liên kết nhiễm sắc thể $X$ hay gặp nhất. ${ }^{1}$ Bệnh hay gặp ở châu Phi, châu Á, Địa Trung Hải và Trung cận đông. ${ }^{2,3}$ G6PD xúc tác bước đầu tiên trong chuyển hóa glucose theo con đường hexose monophosphate, tạo ra NADPH giứ cho glutathion ở dạng khử. Glutathion bảo vệ hồng cầu khỏi tác nhân oxy hóa. Bệnh thiếu G6PD có thể gây huyết tán nặng, vàng da nặng, vàng da nhân, gây tử vong và thương tổn thần kinh ở trẻ sơ sinh. Sàng lọc thiếu G6PD ở trẻ sơ sinh cho phép bác sĩ nhi khoa chẩn đoán và có biện pháp phòng ngừa, điều trị thích hợp từ rất sớm, nhờ vậy giảm thiểu các tình trạng vàng da nặng liên quan đến thiếu G6PD ở trẻ sơ sinh. Tổ chức $Y$ tế Thế giới đã khuyến cáo nên sàng lọc tất cả trẻ sơ sinh ở những vùng có tỷ lệ nam thiếu hụt G6PD từ

Tác giả liên hệ: Trần Thị Chi Mai,

Trường Đại học Y Hà Nội

Email: tranchimai@hmu.edu.vn

Ngày nhận: 30/06/2021

Ngày được chấp nhận: 18/07/2021
$3 \%-5 \%$ trở lên. ${ }^{2-5}$

Các phương pháp sàng lọc thiếu G6PD bao gồm phương pháp hóa sinh (đánh giá hoạt độ G6PD) và phương pháp sinh học phân tử. Phương pháp sinh học phân tử có ưu điểm là sàng lọc được nhóm nữ dị hợp tử, tuy nhiên không phải tất cả các trường hợp nữ dị hợp tử đều thiếu G6PD, một số dạng đột biến hiếm gặp không đưa vào sàng lọc, phương pháp phức tạp, mất nhiều thời gian và công sức, giá thành cao hơn. ${ }^{6}$ Do vậy phương pháp hóa sinh được sử dụng rộng rãi hơn do lợi ích, tính đơn giản, độ tin cậy, độ nhạy của nó đã được khẳng định. ${ }^{6}$ Tại Bệnh viện Nhi Trung ương, sàng lọc thiếu G6PD bằng phương pháp đo hoạt độ enzym trong mẫu máu thấm khô bằng kit của Perkin Elmer đã được áp dụng. Câu hỏi đặt ra là liệu giá trị ngưỡng được khuyến cáo bởi nhà sản xuất có thực sự thích hợp trong việc phát hiện chính xác trẻ có kết quả sàng lọc dương tính hay không. Do vậy, nghiên cứu này được tiến hành nhằm đánh giá giá trị của phương pháp sàng lọc này và xác định giá trị ngưỡng tối ưu cho phòng xét nghiệm. 


\section{II. ĐỐI TƯƠ'NG VÀ PHƯƠNG PHÁP}

\section{1. Đối tượng}

Trẻ sơ sinh đủ tháng từ 24 đến 72 giờ tuổi.

\section{Phương pháp}

Phương pháp chọn mẫu: chọn mẫu thuận tiện. 5680 trẻ sơ sinh đủ tiêu chuẩn được chỉ định làm xét nghiệm sàng lọc sơ sinh tại Bệnh viện Nhi Trung ương trong thời gian từ tháng 10/ 2019 đến tháng $5 / 2020$.

Tiêu chuẩn chọn mẫu nghiên cứu: Mẫu máu đảm bảo được lấy đúng quy trình, đúng thời gian (24 - 72 giờ tuổi) và đủ số lượng quy định. Mẫu được lấy trên trẻ sơ sinh đủ tháng từ 24 đến 72 giờ tuổi. Sau khi lấy, bệnh phẩm được chuyển đến phòng xét nghiệm trong vòng 24 giờ.

Tiêu chuẩn loại trừ mẫu nghiên cứu: Mẫu lấy không đủ số lượng hoặc quá nhiều làm lan sang các ô khác, mẫu không đủ thông tin.

Nguyên lý kỹ thuật sàng lọc bệnh thiếu G6PD: Đo hoạt độ G6PD bằng phương pháp huỳnh quang.

Glucose - 6 - phosphate Dehydrogenase xúc tác phản ứng oxy hóa Gluco - 6 - phosphat thành 6 - phosphogluconat, đồng thời làm $\mathrm{NADP}^{+}$chuyển thành NADPH. G6PD trong mẫu máu khô xúc tác phản ứng trong vòng 30 phút ở nhiệt độ phòng. Đồng sufat được thêm vào để làm chậm phản ứng lại. Hoạt độ enzym G6PD được xác định bằng cách đo huỳnh quang kích thích tại bước sóng 355nm và huỳnh quang phát xạ tại bước sóng 460nm.

Glucose - 6 - phosphat + NADP $\rightarrow$ gluconate $-6-\mathrm{P}+\mathrm{NADPH}^{*}+\mathrm{H}^{+}$

Sản phẩm tạo thành NADPH là chất phát huỳnh quang.

Trang thiết bị, hóa chất và chất liệu nghiên cứu:

- Máy đục lỗ giấy thấm máu khô.

- Hệ thống máy Perkin Elmer: máy lắc ủ, máy rửa, máy đọc.

- Kit sàng lọc bệnh thiếu G6PD của Perkin Elmer.

- Mẫu QC của Perkin Elmer, mẫu ngoại kiểm sàng lọc sơ sinh của CDC.

\section{Đánh giá kết quả sàng lọc}

Tiến hành sàng lọc bệnh thiếu G6PD cho các trẻ sơ sinh sử dụng các mẫu máu thấm khô. Áp dụng giá trị ngưỡng của nhà sản xuất để đánh giá kết quả sàng lọc dương tính và âm tính: kết quả âm tính khi hoạt độ G6PD $\geq 2,6$ $\mathrm{IU} / \mathrm{gHb}$. Các trường hợp sàng lọc dương tính được làm xét nghiệm khẳng định chẩn đoán bằng đo hoạt độ G6PD hồng cầu từ mẫu máu tĩnh mạch. Tính độ nhạy, độ đặc hiệu, giá trị dự đoán dương tính, giá trị dự đoán âm tính, tỷ số khả dĩ dương, tỷ số khả dĩ âm của kỹ thuật sàng lọc.

Tỷ lệ khả dĩ dương (LR+) được định nghĩa là xác suất của một cá nhân mắc bệnh có xét nghiệm dương tính chia cho xác suất của một cá nhân không mắc bệnh có xét nghiệm dương tính hay có thể được tính đơn giản bằng cách chia độ nhạy cho (1 - độ đặc hiệu). LR+ = Se/ (1 - Sp).

Tỷ lệ khả dĩ âm (LR-) được định nghĩa là xác suất của một cá nhân mắc bệnh có xét nghiệm âm tính chia cho xác suất của một cá nhân không mắc bệnh có xét nghiệm âm tính hay có thể được tính đơn giản bằng cách chia (1 - độ nhạy) cho độ đặc hiệu. LR - = (1 - Se)/Sp

Áp dụng phân tích đường cong ROC để xác định giá trị cut - off tại đó độ nhạy, độ đặc hiệu của xét nghiệm sàng lọc là tối ưu, đồng thời đánh giá độ chính xác trong sàng lọc của mỗi xét nghiệm. AUC (diện tích dưới đường cong) > 0,9: xét nghiệm có độ chính xác cao trong sàng lọc, AUC 0,7 - 0,9: xét nghiệm có độ chính xác trung bình trong sàng lọc, AUC 0,5 - 0,7: xét nghiệm có độ chính xác thấp trong sàng lọc.

\section{Xử lý số liệu}

Số liệu thu thập được xử lý bằng các thuật toán thống kê thích hợp trên phần mềm SPSS 20.0 . 


\section{3. Đạo đức trong nghiên cứu}

Tuân thủ nghiêm ngặt các quy định trong nghiên cứu y, sinh học như: trước khi nghiên cứu đối tượng nghiên cứu phải được thông báo và nói rõ mục đích nghiên cứu. Chỉ nghiên cứu ở người tự nguyện. Giữ bí mật về tình trạng sức khỏe của đối tượng tham gia nghiên cứu.

\section{KÉT QUẢ}

Nghiên cứu tiến hành sàng lọc cho 5680 trẻ sơ sinh tuổi từ 24 - 72 giờ, gồm 2768 trẻ nữ và 2912 trẻ nam.

Bảng 1. Hoạt độ G6PD trong mẫu máu thấm khô của trẻ sơ sinh được sàng lọc

\begin{tabular}{lcccc}
\hline \multirow{2}{*}{\multicolumn{1}{c}{ Kết quả sàng lọc }} & \multirow{n}{*}{} & \multicolumn{3}{c}{ Hoạt độ G6PD (IU/g Hb) } \\
\cline { 3 - 5 } & & Trung vị & Min & Max \\
\hline Theo dõi thiếu G6PD (dương tính) & 46 & 1,2 & 0,1 & 2,53 \\
\hline Không thiếu G6PD (âm tính) & 5634 & 5,3 & 2,6 & 9,5 \\
\hline
\end{tabular}

Sử dụng ngưỡng 2,6 IU/g Hb của nhà sản xuất khuyến cáo, 46 trẻ sàng lọc có kết quả theo dõi thiếu G6PD. Hoạt độ G6PD thấp nhất của nhóm sàng lọc dương tính là $0,1 \mathrm{IU} / \mathrm{g} \mathrm{Hb}$, cao nhất là 2,53 IU/g Hb. 46 trẻ có kết quả dương tính được mời đến thăm khám lâm sàng và lấy máu để đo hoạt độ G6PD hồng cầu.

Bảng 2. Hoạt độ G6PD hồng cầu của trẻ sàng lọc dương tính bệnh thiếu G6PD

\begin{tabular}{|c|c|c|c|c|}
\hline \multirow{2}{*}{ Kết quả sàng lọc dương tính } & \multirow{2}{*}{$\mathbf{n}$} & \multicolumn{3}{|c|}{ Hoạt độ G6PD hồng cầu (IU/10 12 hồng cầu) } \\
\hline & & Trung vị & Min & Max \\
\hline Dương tính thật & 45 & 35,8 & 0,64 & 170,0 \\
\hline Dương tính giả & 1 & \multicolumn{3}{|c|}{ Hoạt độ G6PD là 256,3 IU/1012 hồng cầu } \\
\hline
\end{tabular}

Tỷ lệ được chẩn đoán xác định bệnh thiếu G6PD (45/46 trẻ) chiếm 97,83\%. Một trẻ được xác định có kết quả sàng lọc dương tính giả.

Bảng 3. Độ nhạy, độ đặc hiệu, giá trị tiên đoán của xét nghiệm sàng lọc bệnh thiếu G6PD

\begin{tabular}{ccccc}
\hline & Độ nhạy (Se) & $\begin{array}{c}\text { Độ đặc hiệu } \\
\text { (Sp) }\end{array}$ & $\begin{array}{c}\text { Giá trị tiên đoán } \\
\text { dương (PPV) }\end{array}$ & $\begin{array}{c}\text { Giá trị tiên đoán } \\
\text { âm (NPV) }\end{array}$ \\
\hline Kết quả & $100 \%$ & $99,98 \%$ & $97,82 \%$ & $100 \%$ \\
\hline Kết quả & Tỷ số khả dĩ dương (LR+) & \multicolumn{2}{c}{ Tỷ số khả dĩ âm (LR - ) } \\
\hline \multicolumn{2}{c}{5000} & \multicolumn{2}{c}{0} \\
\hline
\end{tabular}

Sử dụng ngưỡng khuyến cáo của nhà sản xuất là 2,6 IU/g Hb, độ nhạy, độ đặc hiệu, giá trị dự đoán âm tính, giá trị dự đoán dương tính xét nghiệm rất tốt. Tỷ số khả dĩ dương cao cho thấy xác suất trẻ mắc bệnh cao khi kết quả sàng lọc dương tính. 


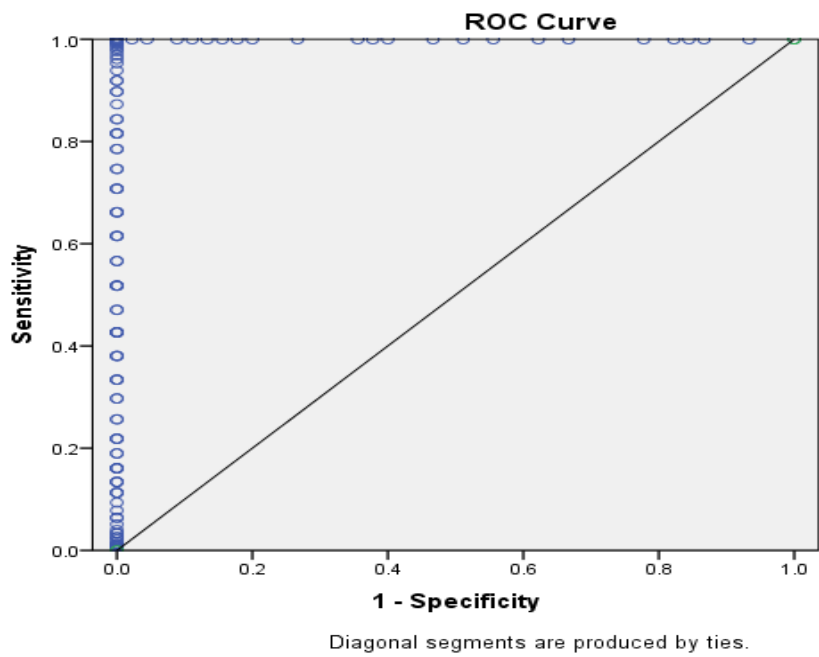

\section{Biểu đồ 1. Biểu đồ ROC đánh giá xét nghiệm sàng lọc thiếu G6PD trên mẫu máu thấm khô}

Xét nghiệm đo hoạt độ G6PD mẫu máu thấm khô trong sàng lọc bệnh thiếu G6PD có diện tích dưới đường cong (AUC) bằng 1 . Tại điểm cắt tối ưu 2,565 IU/g Hb, độ nhạy và độ đặc hiệu trong chẩn đoán thiếu G6PD đều là $100 \%$.

\section{BÀN LUẦN}

Nghiên cứu này đã sàng lọc 5680 trẻ so sinh trong khoảng thời gian 8 tháng. Kết quả thu được 46 trẻ có kết quả sàng lọc dương tính khi áp dụng ngưỡng của nhà sản xuất (kết quả dương tính khi hoạt độ G6PD < 2,6 IU/g $\mathrm{Hb})$. Các trường hợp này được mời đến khám lâm sàng và đo hoạt độ G6PD huyết thanh; 45 trẻ sơ sinh được chẩn đoán thiếu G6PD và 1 trẻ không mắc bệnh. Độ nhạy $100 \%$ có nghĩa xét nghiệm sẽ phát hiện được hầu hết trẻ mắc thiếu G6PD nhưng độ đặc hiệu thấp hơn $(99,98 \%)$ nên vẫn có thể xảy ra dương tính giả đối với một số trẻ không thực sự mắc. Độ nhạy và độ đặc hiệu không thể sử dụng để ước tính xác suất mắc bệnh ở từng bệnh nhân. Tuy nhiên, giá trị tiên đoán âm tính hay dương tính của một xét nghiệm cho chúng ta thông tin về khả năng mắc bệnh khi bệnh nhân có kết quả xét nghiệm. Giá trị tiên đoán dương tính (PPV) cho thấy xác suất trẻ mắc bệnh là 97,82\% khi trẻ có xét nghiệm sàng lọc dương tính với thiếu G6PD; tương tự giá trị tiên đoán âm tính (NPV) là 100\% có nghĩa xác suất trẻ không mắc bệnh khi kết quả sàng lọc âm tính là $100 \%$. Trong nghiên cứu này, tỷ lệ trẻ mắc trong 8 tháng được ước tính là $0,79 \%$ (45 trẻ mắc thực sự trên 5680 trẻ sơ sinh sàng lọc). Một nghiên cứu ở Quảng Tây, Trung Quốc từ năm 2013 đến 2017 đánh giá về tỷ lệ thiếu G6PD chung là $7,28 \%$. Tỷ lệ này cao hơn so với báo cáo ở các tỉnh khác của Trung Quốc như Quý Châu (1,94\%), Quảng Châu (3,7\%), Triều Châu $(2,68 \%)$ và Giang Tây $(3,6 \%)$, trong khi con số tương tự ước tính ở Hy Lạp $(7,7 \%)$ và Ân Độ $(7,8 \%){ }^{5}$ Tỷ lệ hiện mắc cao này có thể liên quan đến các đối tượng nghiên cứu thuộc các dân tộc khác nhau và phương pháp chẩn đoán xác định được áp dụng. Như vậy, với tỷ lệ mắc thấp trong thời gian nghiên cứu ngắn, số lượng trẻ được sàng lọc chỉ ở Hà Nội và một số tỉnh lân cận nên tỷ lệ này chưa đại diện được cho vùng miền hay đất nước. Trong một nghiên cứu về tỷ lệ thiếu G6PD ở miền Bắc Việt Nam, cho thấy tỷ lệ mắc bệnh chủ yếu gặp ở các nhóm dân tộc 
sống ở chân núi, nơi từng có mức độ lây truyền bệnh sốt rét cao, dao động từ $9,7 \%$ đến $31 \%{ }^{7}$ Vì vậy không thể áp dụng trực tiếp giá trị tiên đoán đã công bố của xét nghiệm cho một quần thể vào nghiên cứu khi tỷ lệ mắc bệnh trong dân số ở từng khu vực khác nhau. Tỷ số khả dĩ là một thước đo được kết hợp từ độ nhạy và độ đặc hiệu, có thể được dùng để ước tính xác suất mắc bệnh cho từng bệnh nhân. Kết quả của phương pháp sàng lọc bệnh thiếu G6PD có tỷ số khả dĩ dương (LR+) là 5000 có nghĩa trẻ mắc bệnh thiếu G6PD có khả năng có kết quả sàng lọc dương tính cao hơn 5000 lần so với những trẻ không mắc bệnh. Hay nói cách khác xét nghiệm sàng lọc có kết quả dương tính có nhiều khả năng xảy ra ở những trẻ mắc bệnh thực sự. Ngược lại, tỷ số khả dĩ âm trong nghiên cứu là $0(<1)$ có nghĩa khả năng có kết quả sàng lọc âm tính khó có thể xảy ra ở trẻ mắc bệnh thiếu G6PD. Trong nghiên cứu của Saif AISaif và cộng sự sàng lọc thiếu G6PD cho 8139 trẻ sơ sinh Ả rập, tỷ lệ trẻ bị thiếu G6PD là $2 \%$. Nghiên cứu này sử dụng máu cuống rốn và so sánh với máu ngoại vi thấy kết quả không có sự khác biệt. Độ nhạy của phương pháp sàng lọc là 98,6\%, độ đặc hiệu là 99,7\%. Giá trị dự đoán dương tính (PPV) là $94,5 \%$ và giá trị dự đoán âm tính (NPV) là $99,5 \% .{ }^{8}$ Kết quả của Saif Alsaif khá tương đồng với kết quả của nghiên cứu này. Như vậy, phương pháp sàng lọc bệnh thiếu G6PD sử dụng trong nghiên cứu có độ nhạy, độ đặc hiệu cao, đồng thời với các tỷ lệ dương tính giả thấp đã góp phần sàng lọc sớm cho trẻ sơ sinh giúp phòng ngừa và điều trị bệnh thiếu G6PD hiệu quả.

Độ nhạy và độ đặc hiệu của xét nghiệm phụ thuộc vào ngưỡng được chọn làm điểm giới hạn cho bình thường hay bất thường. Đường cong ROC được chấp nhận rộng rãi như một phương pháp để chọn điểm cut - off tối ưu cho các phương pháp xét nghiệm và để so sánh độ chính xác của các xét nghiệm. Đường cong ROC có diện tích dưới đường cong $(A \cup C)$ bằng 1 phản ánh mức độ tốt của xét nghiệm trong việc phân biệt giữa trẻ mắc bệnh và không mắc bệnh (biểu đồ 1$)$. Dựa trên kết quả biểu đồ đường cong ROC, ở giá trị 2,565 IU/g Hb xét nghiệm cho độ nhạy và độ đặc hiệu đều là $100 \%$. Đây là giá trị ngưỡng tối ưu nhất cho xét nghiệm, giúp xác định được tất cả những trẻ mắc bệnh và không mắc bệnh. Giá trị này rất gần với giá trị ngưỡng 2,6 IU/g Hb mà nhà sản xuất khuyến cáo.

Giá trị cut - off do nhà sản xuất đưa ra sử dụng hiện nay vẫn được áp dụng trên cả trẻ sơ sinh nam và trẻ sơ sinh nữ. Gen G6PD nằm trên nhiễm sắc thể $X$, do đó ở nam chỉ xảy ra hai trường hợp bình thường hoặc thiếu G6PD; nhưng ở nữ có hai nhiễm sắc thể $X$ nên sẽ có hai trường hợp: một là người mang gen đồng hợp (có thể bình thường hoặc thiếu G6PD) và hai là mang gen dị hợp (có khả năng thiếu hụt một phần). Một số nghiên cứu hiện nay đã áp dụng giá trị ngưỡng riêng cho trẻ sơ sinh trai và trẻ sơ sinh gái. Trẻ sau khi sàng lọc có kết quả nghi ngờ thiếu G6PD được xét nghiệm đo hoạt độ G6PD hồng cầu và phân tích đột biến gen G6PD. Ở Quảng Tây sàng lọc thiếu G6PD áp dụng giá trị ngưỡng dao động 2,1 - 2,6 IU/ $\mathrm{gHb}$ chỉ phân biệt được trẻ bình thường hoặc trẻ thiếu G6PD, trong đó bỏ sót một tỷ lệ đáng kể trẻ sơ sinh gái có mang gen dị hợp tử có khả năng thiếu hụt G6PD một phần. Giá trị giới hạn tốt nhất cho hoạt độ G6PD ở trẻ trai là 2,2 IU/g $\mathrm{Hb}$; tuy nhiên, ở trẻ gái, giá trị giới hạn được tìm thấy là 2,8 IU/gHb (độ nhạy: $97,5 \%$, độ đặc hiệu: 87,7\%, AUC: 0,964) để phân biệt tốt nhất giữa thể bình thường và dị hợp tử. ${ }^{5}$ Vì vậy, các giá trị giới hạn để sàng lọc thiếu G6PD cần phân biệt và tối ưu hóa hơn cho hai giới. Trong một báo cáo ở Quảng Châu, sử dụng giá trị ngưỡng của G6PD < 2,6 IU/g Hb, tổng số 687 
$(4,2 \%)$ trẻ sơ sinh có kết quả sàng lọc dương tính, bao gồm 560 (6,4\%) nam và $127(1,7 \%)$ nữ. Trong số các trẻ sơ sinh có kết quả sàng lọc dương tính, 214 nam và 122 nư được chọn ngẫu nhiên để phân tích gen G6PD. Dựa trên kết quả phân tích gen, sàng lọc sơ sinh thiếu G6PD với giá trị ngưỡng G6PD $<2,6 \mathrm{IU} / \mathrm{g} \mathrm{Hb}$ mang lại giá trị dự đoán dương tính (PPV) là 93,5\%, tỷ lệ dương tính giả là $0,5 \%$ và độ nhạy là $99 \% .{ }^{9}$ Hạn chế của nghiên cứu này chưa xác định được giá trị ngưỡng cho mỗi giới nam và nữ do chưa phân tích đột biến gen cũng như đo hoạt độ G6PD ở các trẻ nữ dị hợp tử.

\section{KÉT LUẬN}

Xét nghiệm sàng lọc thiếu G6PD bằng đo hoạt độ enzym trên mẫu máu thấm khô sử dụng kit của Perkin Elmer có giá trị tốt. Phân tích đường cong $\mathrm{ROC}$ xét nghiệm sàng lọc G6PD có diện tích dưới đường cong bằng 1 , tại điểm cắt 2,565 IU/gHb, độ nhạy và độ đặc hiệu đều là $100 \%$.

\section{TÀI LIẸU THAM KHẢO}

1. Cappellini MD, Fiorelli G. Glucose - 6 phosphate dehydrogenase deficiency. Lancet. 2008; 5(371): 64-74.

2. Pao M, Kulkarni A, Gupta V, Kaul S, Balan S. Neonatal screening for glucose - 6 - phosphate dehydrogenase deficiency. The Indian Journal of Pediatrics. 2005;72(10):835 837.

3. Bernardo J, Nock M. Pediatric Provider Insight Into Newborn Screening for Glucose
- 6 - Phosphate Dehydrogenase Deficiency. Clinical Pediatrics. 2014;54(6):575 - 578.

4. Joseph R, Ho L, Gomez J, Rajdurai V, Sivasankaran S, Yip Y. Mass newborn screening for glucose - 6 - phosphate dehydrogenase deficiency in Singapore. The Southeast Asian journal of tropical medicine and public health. 1999;30:70 - 71.

5. Fu C, Luo S, Li Q, et al. Newborn screening of glucose - 6 - phosphate dehydrogenase deficiency in Guangxi, China: determination of optimal cutoff value to identify heterozygous female neonates. Scientific Reports. 2018;8(1): 833.

6. Kaplan M, Hammerman C. Neonatal Screening for Glucose - 6 - Phosphate Dehydrogenase Deficiency: Biochemical Versus Genetic Technologies. Seminars in perinatology. 2011; 35(3): 155 - 161

7. Verle $P$, Nhan $D$, Tinh $T$, et al. Glucose - 6 - phosphate dehydrogenase deficiency in northern Vietnam. Tropical Medicine \& International Health. 2000;5(3):203 - 206.

8. AlSaif S, Ponferrada MB, AlKhairy K, et al. Screening for glucose - 6 - phosphate dehydrogenase deficiency in neonates: a comparison between cord and peripheral blood samples. BMC pediatrics. 2017;17(1):159.

9. Tang $F$, Huang $Y L$, Jiang $X$, et al. Evaluations of newborn screening program performance and enzymatic diagnosis of glucose - 6 - phosphate dehydrogenase deficiency in Guangzhou. Chinese journal of pediatrics. 2018;56(5): 359 - 363.

\section{Summary}

\section{GLUCOSE - 6 - PHOSPHATE DEHYDROGENASE DEFICIENCY SCREENING BY ENZYMATIC ASSAY ON DRY BLOOD SPOT}

Screening for G6PD deficiency in newborn allows pediatricians to diagnose, take appropriate precautions and implement early treatment, thereby minimizing severe jaundice associated with 
G6PD deficiency in infants. This study was conducted to evaluate the validity of measuring enzyme activity on a dry blood sample to screen for G6PD deficiency. Analysis of the ROC curve showed that the test had an area under the curve of 1 . At the optimal cut - off point $2,565 \mathrm{IU} / \mathrm{g} \mathrm{Hb}$, the sensitivity and specificity in the diagnosis of G6PD deficiency were $100 \%$. The enzyme activity test on a dry blood sample using the Perkin Elmer kit is valid in the G6PD deficiency screening. Keywords: G6PD deficiency, Newborn screening, dry blood spot, enzyme activity measurement 